Research Article

\title{
Study on Preparation of Coal Gangue-Based Geopolymer Concrete and Mechanical Properties
}

\author{
Daming Zhang $\mathbb{D}^{1,2}$ Fangjin Sun ${ }^{1 D},{ }^{3,4}$ and Tiantian Liu ${ }^{5}$ \\ ${ }^{1}$ College of Information Science and Engineering, Guilin University of Technology, Guilin 541006, China \\ ${ }^{2}$ Guangxi Key Laboratory of Embedded Technology and Intelligence, Guilin 541006, China \\ ${ }^{3}$ Guangxi Key Laboratory of Geomechanics and Geotechnical Engineering, Guilin University of Technology, Guilin 541004, China \\ ${ }^{4}$ College of Civil Engineering and Architecture, Guilin University of Technology, Guilin 541004, China \\ ${ }^{5}$ College of Civil Engineering, Liaoning Technical University, Fuxin 123000, China \\ Correspondence should be addressed to Fangjin Sun; e_dm@163.com
}

Received 7 May 2021; Revised 1 June 2021; Accepted 12 June 2021; Published 24 June 2021

Academic Editor: Prinya Chindaprasirt

Copyright ( 2021 Daming Zhang et al. This is an open access article distributed under the Creative Commons Attribution License, which permits unrestricted use, distribution, and reproduction in any medium, provided the original work is properly cited.

\begin{abstract}
Alkaline dry powder activator, coal gangue, fly ash, and other raw materials are utilized to prepare coal gangue-based geopolymer concrete. The procedures of making the coal gangue-based geopolymer concrete are illustrated firstly. Also, basic mechanical properties, such as compressive strength and flexural strength of the geopolymer concrete, are studied through mechanical tests. The basic mechanical properties of ordinary concrete and coal gangue-based geopolymer concrete with different activation methods were compared and analyzed. Effects of curing temperature, curing time, water-binder ratio, and sand ratio on the basic mechanical properties of coal gangue-based geopolymer concrete activated by alkaline dry powder were studied. The optimal curing temperature, water-binder ratio, and sand ratio range of coal gangue-based geopolymer concrete activated by alkaline dry powder are obtained, respectively.
\end{abstract}

\section{Introduction}

"Let's get this on the table right away, without mincing words. With regard to the climate crisis, yes, it's time to panic" [1]. So, it is high time for us to realize resource efficiency related environmental degradation. Concrete is the main raw material of the construction industries, and most traditional concrete uses Portland cement as cementing material. As the huge demand in infrastructure systems, production of the most common infrastructure materials has grown, with the pace of cement production outstripping not only all other materials but also population growth [2-5]. This upturn in materials production is a cause for concern regarding environmental impact. In 2012 alone, the production of cement was approximately 3.8 gigatonnes $(\mathrm{Gt})$, equivalent to approximately $3.2 \mathrm{Gt}$ of $\mathrm{CO}_{2}$ emissions worldwide, approximately $8 \%$ of the annual anthropogenic $\mathrm{CO} 2$ emissions [6]. In three years, the production of cement globally rose to over $4.5 \mathrm{Gt}$ [7] and with it, so did $\mathrm{CO}_{2}$ emissions. Portland cement is considered to be the primary contributor to greenhouse gas emissions because of the large proportion of greenhouse gas emissions inherent in cement chemical property and the high-temperature treatment required for its synthesis. Therefore, only by fundamentally changing the chemical properties and synthetic pathways of building materials can be reduced the greenhouse gas emissions and environmental pollution. Silicate cement has high energy consumption and serious pollution in the production process. The emergence of geopolymer prepared from coal gangue waste, a new environmental production material, undoubtedly provides a value-added method for such industrial while overcoming the shortcomings of traditional concrete such as high energy consumption and heavy pollution, opening up new prospects and directions. Geopolymer prepared with different industrial wastes is a new type of cementitious material. It is relatively friendly to the environment and has little pollution while improving the utilization rate of industrial wastes, paving a way for green 
concrete making [8-10]. Geopolymers are synthesized by the reaction of solid silicate or silicoaluminate powder with alkali hydroxide/alkaline silicate [11]. Coal gangue is the largest solid waste discharged and occupied in China. Most coal gangue contains clay minerals and has a similar chemical composition to clay, which can be used as raw materials for the preparation of geopolymer and geopolymer concrete $[12,13]$. The alkaline solution is usually used as an activator for making geopolymer. A traditional alkaline solution is viscous and corrosive, and there is a certain risk in its use in the preparation or test process $[14,15]$. At the same time, it is not convenient to use alkaline activation solution in the mass production of geopolymer due to its strong corrosiveness and difficulties in transportation, especially for a long distance. The authors have proposed a coal ganguebased geopolymer activated by an alkaline dry powder activator [16]. In the work here, based on the coal ganguebased geopolymer, a block of new geopolymer concrete is proposed and the basic mechanical properties are studied.

For now, scholars at home and abroad have carried out some research on geopolymer, but research on geopolymer concrete is not so much. The raw materials for preparation are mainly fly ash or bottom ash, and the activation method is a mainly alkaline solution. Although the field of alkaliactivated materials begun more than 100 years ago, there are still many problems to be further studied. Kusbiantoro et al. [17] mixed fly ash and husk ash (referred to as RHA) as raw materials for geopolymer concrete and studied the strength test from three different hardening times, external curing temperature, external corrosion environment, and oven curing. The results showed that high temperature increased the decomposition of silica and alumina produced by the polarization of hydrogen and oxygen molecules in fly ash. Ulhaq et al. [18] used fly ash and bottom ash to study the geological polymerization of concrete. Through the FT-IR study, they observed that some ash powders themselves showed very small bands because the resonance of siliconoxygen-silicon was very small. However, when they were used in concrete, those vibrations reached a very high level, indicating that these ash powders had a positive impact on geopolymer. The results show that the scope and degree of geological polymerization reaction are higher when fly ash is compared with bottom ash. In 2010, Temuujin et al. [19] studied the performance of fly ash-based geopolymeric concrete with different proportions of sand aggregate. The compressive strength of concrete samples at 7 days was analyzed by NMR. The results showed that $66 \%$ of aluminum was surrounded by four sides and $34 \%$ by eight sides. It was concluded that fly ash had a positive impact on the polymerization reaction involving aluminum ions and geological polymers that could be used as raw materials. Hardjito et al. [20] studied the fly ash-based polymer concrete (GPC), compressive strength range between 30 and $80 \mathrm{MPa}$, and the slump changes from 100 to $250 \mathrm{~mm}$ (activator strength: $8-14 \mathrm{M}$ ). When the curing temperature is $90^{\circ} \mathrm{C}$, the optimal strength can be obtained when the solid ratio of water to geological polymer is 0.18 . Fernandez-Jimenez et al. [21] manufactured fly ash-based polymer concrete with $45 \mathrm{MPa}$ compressive strength. They observed that GPC had a much lower elastic modulus $(18.4 \mathrm{GPa})$ than OPC concrete (30.3 GPa). Olivia and Nikraz [22] solidified the fly ashbased polymer concrete mixture at different temperatures in the range of $60-75^{\circ} \mathrm{C}$ under the compressive strength of $55 \mathrm{MPa}$ for 28 days. The hardened mixture has high tensile strength and bending strength, and the resulting expansion is small. The elastic modulus is $15-29 \%$ lower than that of the OPC concrete mixture. Laskar and Bhattacharjee [23] studied the rheological properties of fil ash-based geopolymer concrete. The slump of fly ash-based geopolymer concrete changed from $25 \mathrm{~mm}$ to flowing concrete with 1-20 M activator strength. They found that the yield stress and plastic viscosity are affected by the molar strength of sodium hydroxide solution and the ratio of silicate to hydroxide solution. The setting time of geopolymer concrete is 120 minutes. Like Portland cement slurry and mortar, geopolymer also has historically dependent rheological characteristics like Bingham fluid; that is, if a period of constant shear occurs before the initial solidification, the geopolymer can maintain the fluid state.

Based on the coal gangue-based geopolymer as the cementitious material, a new type of coal gangue-based geopolymer concrete is proposed. Ordinary cement concrete is used as the reference standard to make the coal ganguebased geopolymer concrete with the same compressive strength grade. The experimental design is carried out to study the mechanical properties. The making procedures are illustrated and the mechanical properties are studied.

\section{Alkaline Dry Powder-Activated Coal Gangue- Based Geopolymer Concrete}

\subsection{Preparation Techniques}

(1) Coal gangue and fly ash required for preparation: the coal gangue in the experiment is the spontaneous combustion coal gangue of Gaode Mine in the Fuxin City, Liaoning Province, and its chemical composition is shown in Table 1 . The fly ash of grade I in Fuxin Power Plant is used in this experiment. The chemical composition is shown in Table 2.

(2) Standard sand: Xiamen Aisiou standard sand was selected. The specific technical indicators are shown in Table 3.

(3) Use of commercial sodium hydroxide and calcium carbonate reagents: the purity of sodium hydroxide is $99 \%$.

(4) Fine aggregate: local river sand (fineness modulus 2.4).

(5) Coarse aggregate: crushed stone (after cleaning and screening, the particle size is $5 \sim 31.5 \mathrm{~mm}$ ).

\subsection{Mixture Ratio of Geopolymer Concrete. Mixture ratio} and optimization design are crucial for the synthesis of highperformance geopolymeric concrete, which determines the characteristics of geopolymer concrete. This chapter only discusses the mixture ratio of coal gangue-based geopolymer concrete, and the optimization design of the mixture 
Table 1: Analysis results of main chemical components of coal gangue (\%).

\begin{tabular}{lccccc}
\hline Compositions & $\mathrm{SiO}_{2}$ & $\mathrm{Al}_{2} \mathrm{O}_{3}$ & $\mathrm{~K}_{2} \mathrm{O}$ & $\mathrm{CaO}$ & $\mathrm{MgO}$ \\
\hline Contents & 65.09 & 16.86 & 2.67 & 2.07 & $\mathrm{~S}$ \\
Compositions & $\mathrm{Fe}_{2} \mathrm{O}_{3}$ & $\mathrm{Na}_{2} \mathrm{O}$ & $\mathrm{TiO}_{2}$ & 0.98 & Loss on ignition \\
Contents & 6.15 & 1.64 & 0.74 & 0.53 & 1.49 \\
\hline
\end{tabular}

TABLe 2: Main chemical components of fly ash.

\begin{tabular}{lccccccccc}
\hline Compositions & $\mathrm{SiO}_{2}$ & $\mathrm{Al}_{2} \mathrm{O}_{3}$ & $\mathrm{CaO}$ & $\mathrm{K}_{2} \mathrm{O}$ & $\mathrm{Na}_{2} \mathrm{O}$ & $\mathrm{MgO}$ & $\mathrm{Fe}_{2} \mathrm{O}_{3}$ & $\mathrm{TiO}_{2}$ & $\mathrm{SO}_{3}$ \\
\hline Contents & 62.02 & 11.29 & 6.07 & 1.63 & 0.13 & 1.56 & 5.19 & 1.00 & 1.04 \\
\hline
\end{tabular}

TABle 3: Technical indicators of standard sand.

\begin{tabular}{lcccccc}
\hline \multicolumn{7}{c}{ Particle sizes range } \\
Size of screen mesh $(\mathrm{mm})$ & 2.0 & 1.6 & 1.0 & 0.5 & 0.16 & 0.08 \\
Cumulative sieve residue $(\%)$ & 0 & 7 & 33 & 67 & 87 & 99 \\
\hline
\end{tabular}

proportion will be studied in the following chapters. The mixture ratio design of geopolymer concrete with alkali dry powder activator by orthogonal design method [24], the aim is to prepare coal gangue-based polymer concrete with good workability, strength, deformation, and durability that can meet the engineering requirements.

In this paper, according to the different content of sodium hydroxide and calcium carbonate in dry powder activator and the geological polymer with sodium hydroxide solution as activator alone, seven kinds of geological polymer concrete with different mixture ratios are designed, and the mix proportion is shown in Table 4.

2.3. Manufacture and Maintenance of Test Block. This section makes ordinary concrete test blocks and geopolymer concrete test blocks for comparison of performance between different concrete test blocks. Three ordinary concrete blocks and eight geopolymer concrete blocks were made for testing. The process of making geopolymer concrete test blocks are as follows:

(1) Firstly, the sodium hydroxide (SH) solution was mixed with calcium carbonate (CC) powder to form a solution consisting of calcium hydroxide $(\mathrm{CH})$, sodium carbonate (SC), and pirssonite $(\mathrm{P})$, which was dried in an oven at $80^{\circ} \mathrm{C}$ for 8 hours.

(2) Then, the powder was crushed to fixed particle size, and the powder with particle size less than $0.03 \mathrm{~mm}$ in the activator powder was taken.

(3) Then, the (spontaneously ignited) coal gangue block crushed by a sledgehammer and then repeatedly crushed into small particles in a crusher. The powder with a particle size between $0.01 \mathrm{~mm}$ and $0.09 \mathrm{~mm}$ was screened.

(4) During the production of the test block, sand and pebble were poured into the mixer and stirred for about $140 \mathrm{~s}$. Then, coal gangue powder and fly ash were poured into the mixer and stirred for the $20 \mathrm{~s}$.
Finally, dry powder activator powder was added and stirred for $120 \mathrm{~s}$.

(5) After mixing, the geopolymer concrete is poured into the mold, vibrated, compacted, and finally smoothed to make the geopolymer concrete test block, as shown in Figure 1.

Compressive strength of ordinary concrete blocks is carried out according to "Standard Test Method for Mechanical Properties of Ordinary Concrete" (GB/T50081-2002) [25]. Because of the rapid hardening rate of geopolymer concrete, it can reach higher strength in a short time. At the same time, to study the influence of curing temperature on the compressive strength of geopolymer concrete, four specimens in the prepared test block were cured as a group in the natural room temperature environment (20-25), and the other four specimens were coated with plastic film as a group and put into the oven for curing. To compare the influence of different curing temperatures on the performance of geopolymer concrete, different curing temperatures were used in the oven. After curing at different ages (3 d, $7 \mathrm{~d}$, and $28 \mathrm{~d}$ ), the compressive strength and flexural strength of all specimens were tested after $1 \mathrm{~d}$ in the room. The final compressive strength and flexural strength were taken as the average value of the same group of specimens.

2.4. Test Methods for Compressive and Flexural Strengths. The compressive and flexural strength tests of geopolymer concrete are carried out according to $<$ Strength Test Method for Mechanical Properties of Ordinary Concrete> [15], and the flexural test adopts four-point bending. The compressive strength test is carried out on the electrohydraulic servo universal testing machine, and the flexural strength test is carried out on the flexural testing machine. In the process of the compressive strength test, continuous and uniform loading was maintained, and the loading speed was maintained at $0.6 \mathrm{MPa} / \mathrm{s}$. When small cracks appeared and the deformation began to damage, the oil inlet valve of the testing machine was stopped until the specimen was destroyed, and the failure load was recorded. The final compressive strength is the average value of the compressive strength of six cube specimens in the same group, which is accurate to $0.1 \mathrm{kN}$. The loading speed of the flexural strength test is $1 / 10$ of the compressive strength test. 
TABLE 4: Mixture ratio of coal gangue-based polymer concrete activated by dry powder $\left(\mathrm{kg} / \mathrm{m}^{3}\right)$.

\begin{tabular}{lcccccccc}
\hline Numbers & Coal gangue & Fly ash & Sodium hydroxide & Calcium carbonate & Sand & Pebble & Water-binder ratio & Percentage of sand \\
\hline G1 & 196 & 196 & 66 & 110 & 583 & 1237 & 0.31 & 0.33 \\
G2 & 196 & 196 & 66 & 120 & 621 & 1248 & 0.33 & 0.33 \\
G3 & 196 & 196 & 66 & 145 & 640 & 1271 & 0.35 & 0.33 \\
G4 & 196 & 196 & 44 & 198 & 574 & 1216 & 0.38 & 0.32 \\
G5 & 196 & 196 & 72 & 198 & 588 & 1248 & 0.41 & 0.33 \\
G6 & 196 & 196 & 98 & 198 & 652 & 1293 & 0.43 & 0.34 \\
G7 & 196 & 196 & 168 & - & 615 & 1253 & 0.30 & 0.33 \\
\hline
\end{tabular}

1: water-binder ratio $=$ quality of dry powder activator/(quality of dry powder activator + quality of coal gangue + quality of fly ash). 2 : percentage of sand $=$ quality of sand/(quality of sand + quality of pebble).

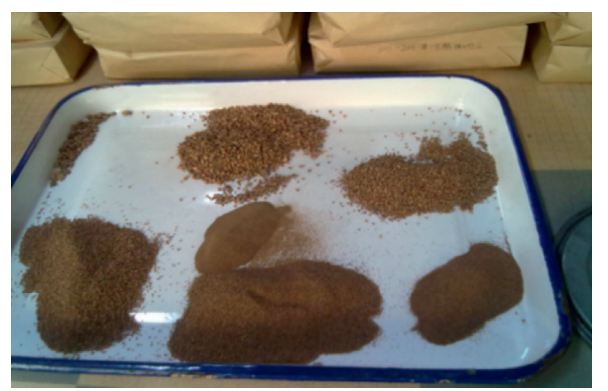

(a)

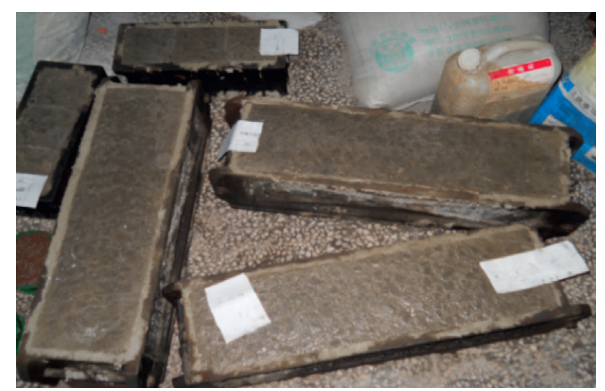

(b)

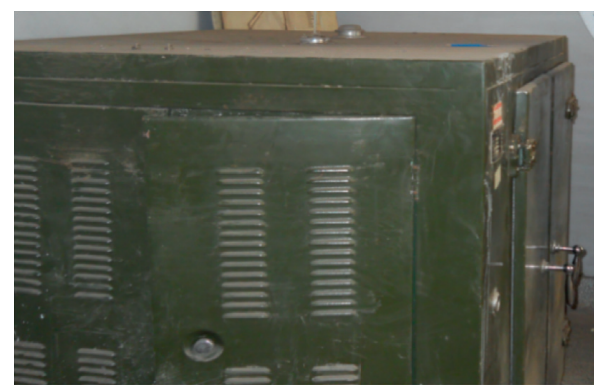

(c)

Figure 1: Production process of test blocks. (a) Raw materials for the experiment. (b) Coal gangue-based geopolymer concrete blocks. (c) Oven curing.

The basic mechanical properties of test materials were tested before the test. The test results of the mechanical properties of geopolymer concrete are shown in Table 5. Among them, the design values of axial compressive strength and axial tensile strength are determined according to the "<Code for design of concrete structures >"; that is, the strength standard value is obtained by dividing the partial coefficient of concrete materials.

\section{Results and Discussion}

3.1. Compressive Strength and Flexural Strength. Concrete cube compressive strength should be calculated by the following formula:

$$
f_{c u}=\frac{F}{A}
$$

here, $f_{c u}$ is the compressive strength of concrete cube specimens $(\mathrm{MPa}), F$ is failure load of the specimen $(\mathrm{N})$, and $A$ is pressure area of specimens $(\mathrm{mm})$.
Tables 6-7 show the compressive strength and flexural strength of geopolymer concrete (GC) specimens cured at room temperature for different times $(7 \mathrm{~d}, 28 \mathrm{~d}$ ) and compared with the compressive strength and flexural strength of ordinary concrete specimens (C).

It can be seen from Tables 6 and 7 that the compressive strength and flexural strength of coal gangue-based geopolymer concrete are higher than those of ordinary concrete under room temperature curing conditions and different curing times, whether using dry powder activation or $\mathrm{NaOH}$ solution activation. Among them, the compressive strength is $28.6 \%$ higher than that of ordinary concrete, and the flexural strength is $24.2 \%$ higher than that of ordinary concrete. This is mainly because the $\mathrm{NaOH}$ contained in the alkali activator accelerates the hardening process of concrete, accelerates the dissolution of silicon and aluminum compounds in its form of sodium silicate and sodium metasilicate, and then reacts with $\mathrm{Ca}(\mathrm{OH})_{2}$ to form calcium silicate and calcium aluminate minerals so that it hardens and regenerates $\mathrm{NaOH}$ to catalyze the next reaction; thus, 
TABLE 5: Mechanical properties of geopolymer concrete.

\begin{tabular}{lccccc}
\hline $\begin{array}{l}\text { Cubic compressive } \\
\text { strength }(\mathrm{MPa})\end{array}$ & $\begin{array}{c}\text { Prism compressive } \\
\text { strength }(\mathrm{MPa})\end{array}$ & $\begin{array}{c}\text { Cleavage } \\
\text { strength } \\
(\mathrm{MPa})\end{array}$ & $\begin{array}{c}\text { Design value of axial } \\
\text { compressive strength } \\
(\mathrm{MPa})\end{array}$ & $\begin{array}{c}\text { Design value of tensile } \\
\text { compressive strength } \\
(\mathrm{MPa})\end{array}$ & $\begin{array}{c}\text { Elastic } \\
\text { modulus } \\
(\mathrm{MPa})\end{array}$ \\
\hline 52.36 & 46.70 & 6.23 & 30.37 & 3.59 & $\begin{array}{c}\text { Poisson's } \\
\text { ratio }\end{array}$ \\
\hline
\end{tabular}

TABLE 6: Compressive strength and flexural strength of each specimen cured for 7 days at room temperature.

\begin{tabular}{|c|c|c|c|c|c|c|c|c|}
\hline Numbers & G1 & G2 & G3 & G4 & G5 & G6 & G7 & $\mathrm{C}$ \\
\hline Compressive strength (MPa) & 59.4 & 52.7 & 46.3 & 45.1 & 64.3 & 44.8 & 39.4 & 35.3 \\
\hline Flexural strength $(\mathrm{MPa})$ & 4.23 & 3.96 & 3.78 & 3.62 & 4.79 & 3.46 & 3.15 & 2.88 \\
\hline
\end{tabular}

TABle 7: Compressive strength and flexural strength of each specimen cured for 28 days at room temperature.

\begin{tabular}{lcccccccc}
\hline Numbers & G1 & G2 & G3 & G4 & G5 & G6 & G7 & C \\
\hline Compressive strength (MPa) & 71.9 & 64.3 & 56.4 & 53.7 & 79.7 & 53.8 & 46.6 & 38.9 \\
Flexural strength (MPa) & 4.79 & 4.54 & 4.36 & 4.31 & 5.89 & 5.52 & 3.57 & 3.21 \\
\hline
\end{tabular}

the strength of geopolymer concrete is higher. It also can be seen that the compressive strength and flexural strength of coal gangue-based polymer concrete with dry powder activator are higher than those of coal gangue-based polymer concrete with $\mathrm{NaOH}$ solution activator. Among them, the compressive strength of coal gangue-based polymer concrete with dry powder activator is $25.1 \%$ higher than that of coal gangue-based polymer concrete with $\mathrm{NaOH}$ solution activator, and the flexural strength is $21.4 \%$ higher on average.

To study the effect of different curing methods on the mechanical properties of coal gangue-based geopolymer concrete, Tables 8 and 9 show the mechanical properties of each specimen when the oven curing temperature is $60^{\circ} \mathrm{C}$.

Analyze the data in Tables 8 and 9 and comparison of compressive strength and flexural strength of geopolymer concrete block cured at room temperature. It can be seen that the compressive strength and flexural strength of geopolymer concrete blocks and ordinary concrete blocks are improved. And 3 days and 7 days of compressive strength and flexural strength increased greatly; among them, the average compressive strength of geopolymer concrete increased by about $20 \%$ in 3 days, and the average increase of flexural strength is about $16 \%$, which is greater than the increase of the strength of ordinary concrete in 3 days. The compressive strength and flexural strength of geopolymer concrete increased by $17 \%$ and $15 \%$ on average in 7 days, which were greater than the increased strength of ordinary concrete in 3 days. The compressive and flexural strength of geopolymer concrete increased by $11 \%$ and $8 \%$ on average in 28 days, respectively, which were greater than the increased strength of ordinary concrete in 3 days. It is shown that increasing curing temperature can greatly improve the early strength of concrete, and the influence of curing temperature on geopolymer concrete is greater, which is due to the promotion of polymerization in a certain range of temperature.

3.2. Effect of Powder Activator on Compressive and Flexural Strengths. Figure 2 is the compressive strength change rule of G1-G3 coal gangue-based geopolymer concrete with different dry powder activator content under natural curing conditions.

It can be seen from Figure 2 that, with the increase of curing time, the compressive strength and flexural strength of coal gangue-based geopolymer concrete increase. Among them, G1, G2, and G3 of geopolymer concrete decrease in turn, which is because the content of calcium carbonate will reduce the content of aluminum silicate in concrete, increasing absorption, thereby reducing the compressive strength of geopolymer concrete.

3.3. Effect of Curing Time on Compressive and Flexural Strengths. Figure 3 shows the influence of different curing times on the compressive strength and flexural strength of coal gangue-based geopolymer concrete activated by dry powder under room temperature curing conditions and compared with the characteristics of geopolymer concrete G7 activated by $\mathrm{NaOH}$ solution.

It can be seen from Figure 3 that the compressive strength and flexural strength of coal gangue-based geopolymer concrete increased with the increase of curing time under room temperature curing conditions, whether using dry powder activated or $\mathrm{NaOH}$ solution activated. It is worth noting that the compressive and flexural strength of geopolymer concrete G5 activated by dry powder activator is greater than that of geopolymer concrete G4 and G6. It can be seen from Table 4 that the content of $\mathrm{NaOH}$ in the dry powder activator of geopolymer concrete G6 is higher than that of geopolymer concrete $\mathrm{G} 5$ and the content of $\mathrm{NaOH}$ in the dry powder activator of geopolymer concrete G4 is less than that of geopolymer concrete G5. It indicates that too large or too small $\mathrm{NaOH}$ content in dry powder activator is not conducive to the development of strength of geopolymer concrete. The reason is that although the higher the concentration of sodium hydroxide is, the stronger the destructive effect on the fracture of $\mathrm{Si}-\mathrm{O}$ and $\mathrm{Al}-\mathrm{O}$ bonds in the polymer is, and the compressive strength increases, the alkalinity also has a certain influence on the curing rate, so too high or too low concentration of sodium hydroxide will 
TABLE 8: Compressive strength and flexural strength of each specimen cured at $60^{\circ} \mathrm{C}$ for 7 days.

\begin{tabular}{|c|c|c|c|c|c|c|c|c|}
\hline Numbers & G1 & G2 & G3 & G4 & G5 & G6 & G7 & $\mathrm{C}$ \\
\hline Compressive strength (MPa) & 68.3 & 71.1 & 54.2 & 59.2 & 86.5 & 52.3 & 45.7 & 38.8 \\
\hline Flexural strength $(\mathrm{MPa})$ & 4.72 & 4.26 & 4.19 & 4.03 & 5.52 & 3.94 & 3.54 & 3.33 \\
\hline
\end{tabular}

TABLE 9: Compressive strength and flexural strength of each specimen cured at $60^{\circ} \mathrm{C}$ for 28 days.

\begin{tabular}{lcccccccc}
\hline Numbers & G1 & G2 & G3 & G4 & G5 & G6 & G7 & C \\
\hline Compressive strength (MPa) & 80.8 & 74.6 & 62.1 & 57.2 & 95.6 & 59.1 & 50.5 & 40.9 \\
Flexural strength (MPa) & 5.06 & 4.86 & 4.73 & 4.52 & 6.24 & 5.90 & 3.81 & 3.39 \\
\hline
\end{tabular}

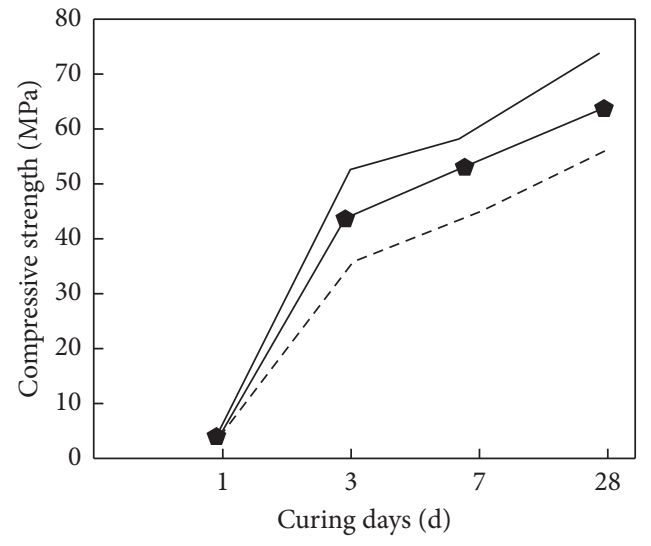

-. - G3

$-\mathrm{G} 2$

- G1

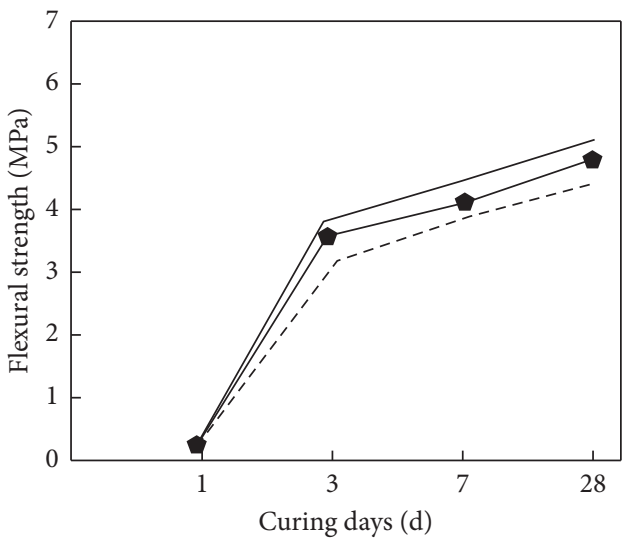

-.- G3

$-\mathrm{G} 2$

(a)

(b)

FIGURE 2: Effects of powder activator on compressive strength and flexural strength of coal gangue-based geopolymeric concrete. (a) Effects on compressive strength. (b) Effects on flexural strength.

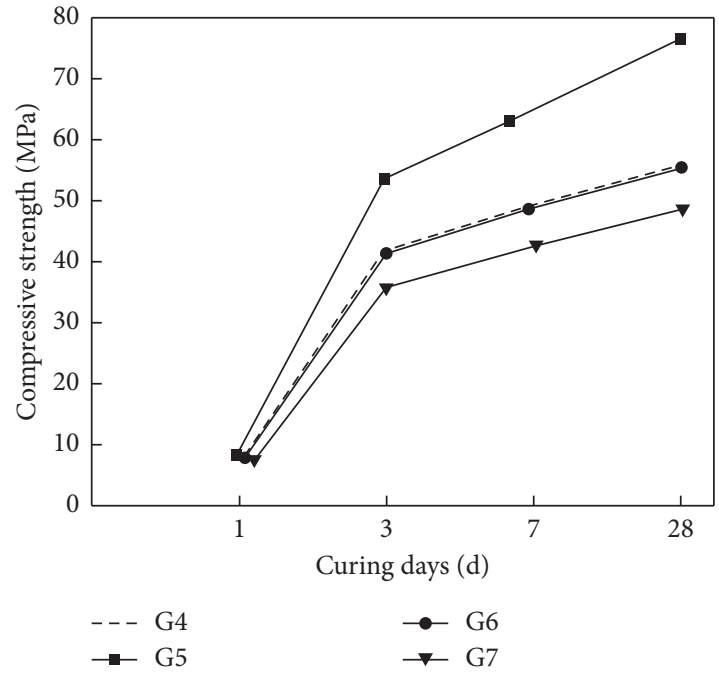

(a)

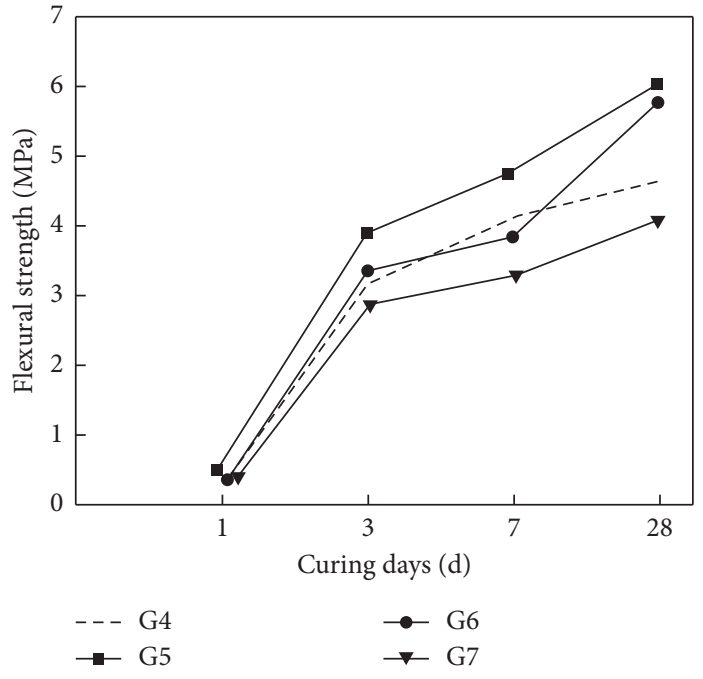

(b)

FIGURE 3: Effect of curing time on compressive strength and flexural strength of coal gangue-based geopolymeric concrete. (a) Effects on compressive strength. (b) Effects on flexural strength. 


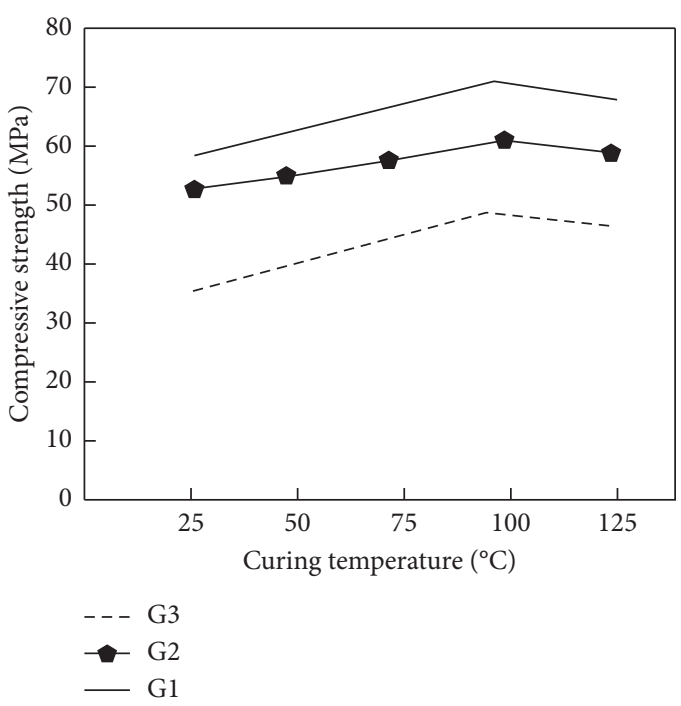

(a)

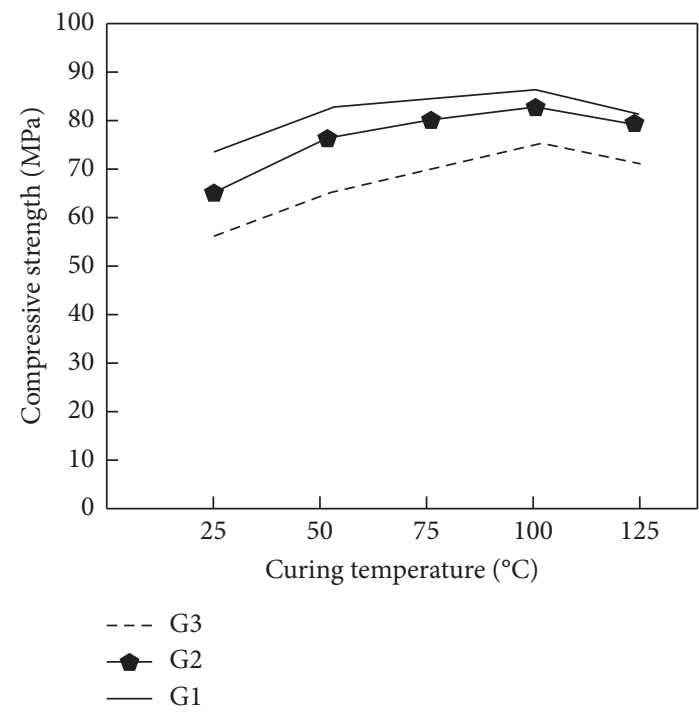

(c)

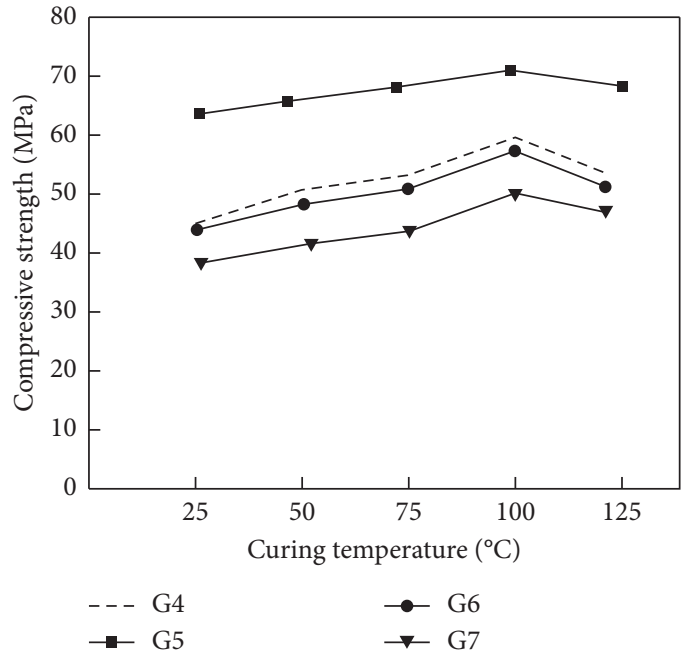

(b)

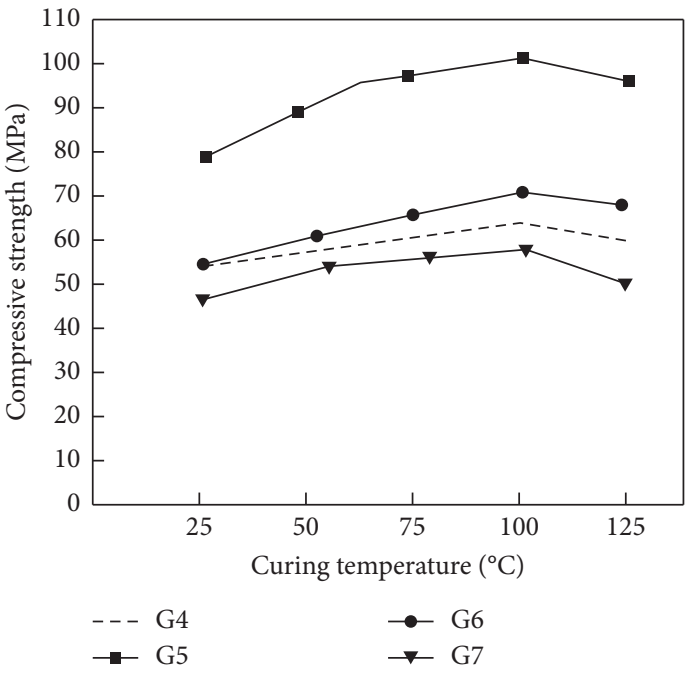

(d)

FIGURE 4: The variation of compressive strength of coal gangue-based polymer concrete with curing temperature. (a) Seven-day compressive strength (G1-G3). (b) Seven-day compressive strength (G4-G7). (c) 28-day compressive strength (G1-G3). (d) 28-day compressive strength (G4-G7).

lead to lower compressive strength. The sodium hydroxide concentration of the dry powder activator in polymer G4 is low and the curing speed is fast, which delays the polymerization reaction and reduces the strength. The high concentration of sodium hydroxide in the dry powder activator of polymer G6 makes it impossible for some coal gangue, fly ash, and sodium hydroxide in the polymer to participate in the reaction, remain in the sample, and lower the strength. It can be seen that the compressive strength and flexural strength of coal gangue-based geopolymer concrete with dry powder activator are greater than those of coal gangue-based geopolymer concrete activated by $\mathrm{NaOH}$ solution. In dry powder activator, sodium hydroxide and calcium carbonate react according to formulas (2) and (3) to obtain more sodium hydroxide. These calcium hydroxides speed up the polymerization process of geopolymer concrete, thereby producing more polymers and hydration products, so geopolymer concrete activated by dry powder activator has higher compressive strength. On the other hand, in the dry powder activator, carbonate (calcium carbonate and sodium carbonate) as a material filler reduces the porosity of geopolymer concrete, thereby reducing the water absorption of the polymer, and promoting the improvement of compressive strength and the flexural strength of geopolymer concrete.

$$
\begin{aligned}
& 2 \mathrm{NaOH}+\mathrm{CaCO}_{3} \rightarrow \mathrm{Na}_{2} \mathrm{CO}_{3}+\mathrm{Ca}(\mathrm{OH})_{2} \\
& \mathrm{Na}_{2} \mathrm{CO}_{3}+\mathrm{CaCO}_{3}+2 \mathrm{H}_{2} \mathrm{O} \rightarrow \mathrm{Na}_{2} \mathrm{Ca}\left(\mathrm{CO}_{3}\right)_{2} \cdot 2 \mathrm{H}_{2} \mathrm{O}
\end{aligned}
$$

\subsection{Effect of Curing Temperature on Compressive Strength and} Flexural Strength. Figures 4 and 5 show the influence of different curing temperatures on the compressive strength 


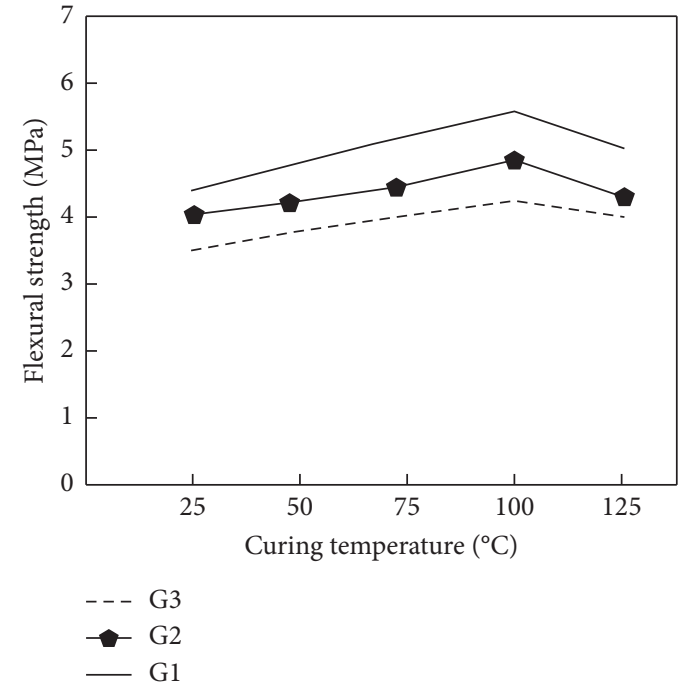

(a)

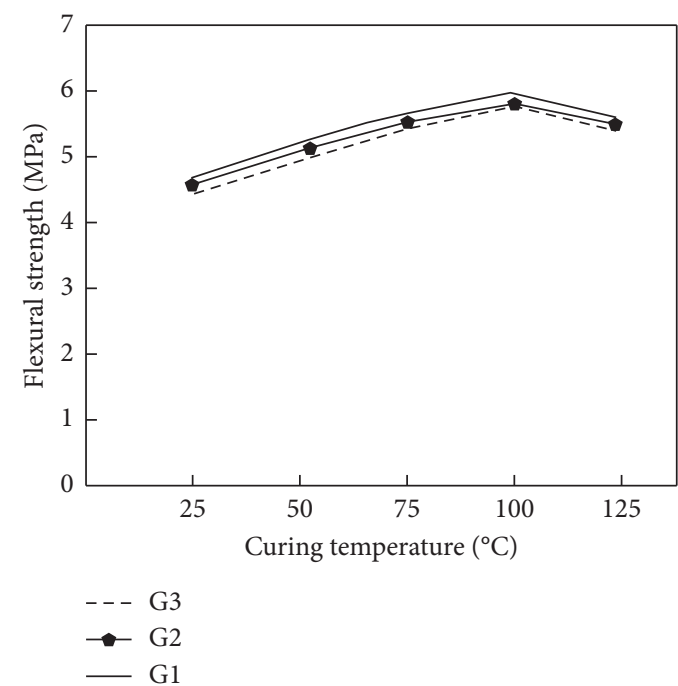

(c)

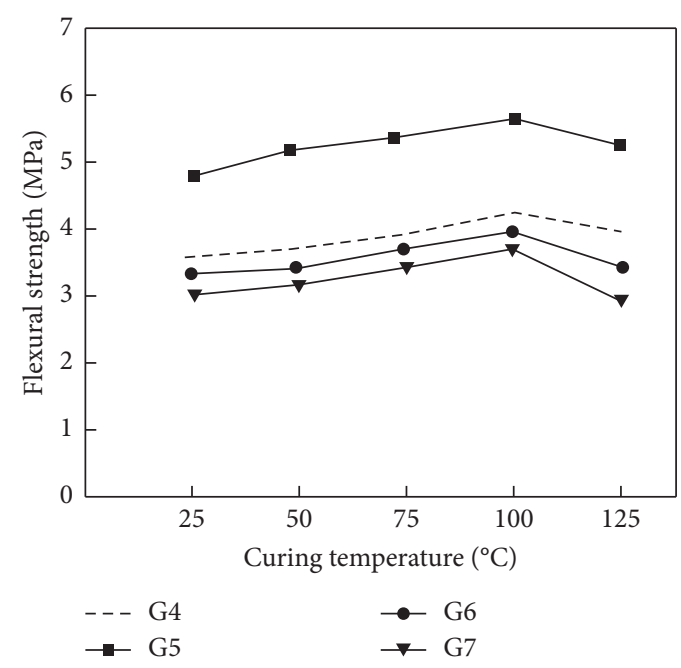

(b)

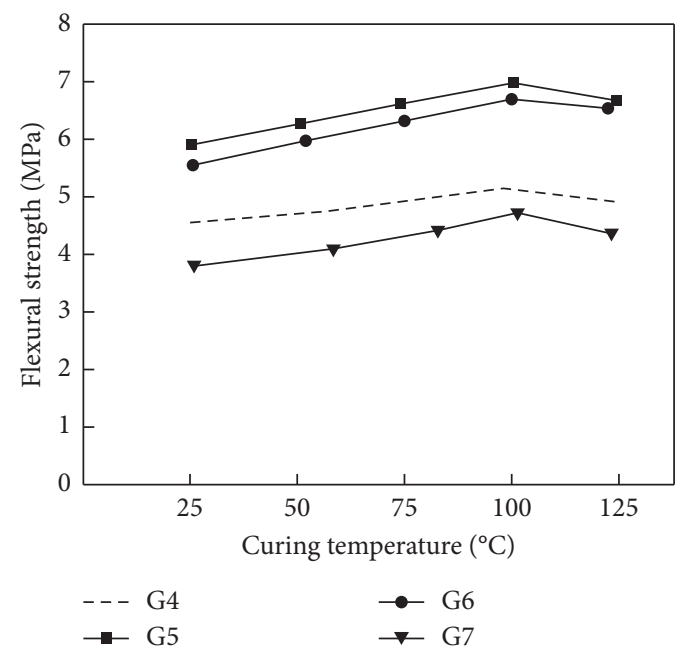

(d)

FIGURE 5: The variation of flexural strength of coal gangue-based polymer concrete with curing temperature. (a) Seven-day flexural strength (G1-G3). (b) Seven-day flexural strength (G4-G7). (c) 28-day flexural strength (G1-G3). (d) 28-day flexural strength (G4-G7).

and flexural strength of coal gangue-based geopolymer concrete activated by dry powder.

It can be seen from Figures 4-5 that the compressive strength and flexural strength of geopolymer concrete G1-G7 increase first and then decrease regardless of the activation mode. When the temperature was less than $100^{\circ} \mathrm{C}$, the compressive strength and flexural strength increase with the increase of curing temperature; when the temperature was higher than $100^{\circ} \mathrm{C}$, the compressive strength and flexural strength decreased with the increase of curing temperature. The reason may be that, with the curing temperature rising, the reaction of dry powder activator or $\mathrm{NaOH}$ solution with coal gangue and fly ash is accelerated; it accelerates the destruction of the network structure of silica-alumina glass in coal gangue and fly ash, resulting in the hardening of geopolymer concrete in a short period time, and a frame structure of coal gangue-based geopolymer concrete was quickly formed; this is unfavorable for the continuation of the geological polymerization reaction. Therefore, the compressive strength and flexural strength of geopolymer concrete at high temperatures greater than a certain curing temperature are relatively low. It can be inferred that the optimum curing temperature of coal gangue-based geopolymer concrete is $100^{\circ} \mathrm{C}$.

3.5. Effect of Water-Binder Ratio on Compressive Strength and Flexural Strength. The changes of compressive strength and flexural strength of geopolymer concrete cured at room temperature with water-binder ratio are studied, as shown in Figures 6 and 7.

It can be seen from Figures 6 and 7 that no matter what activation method is adopted when the water-binder ratio varies from 0.30 to 0.43 , the compressive strength and 


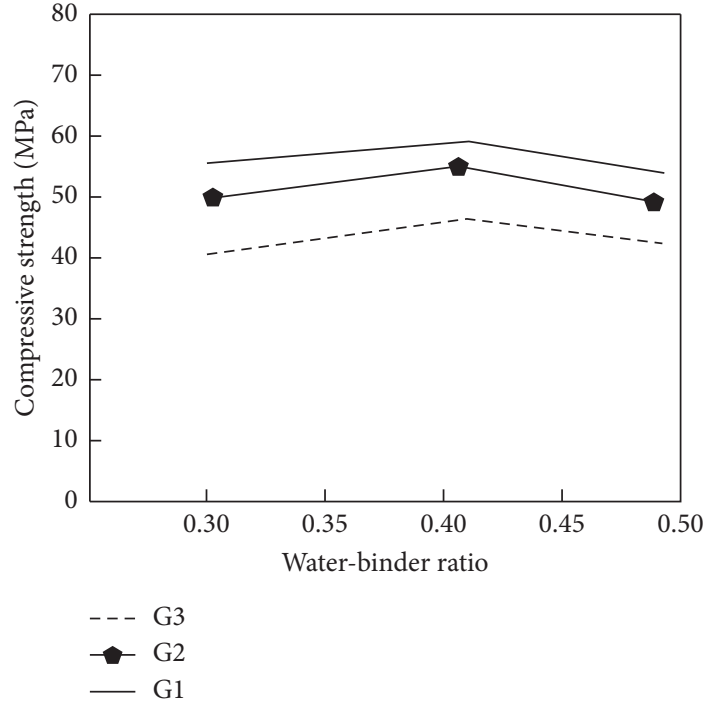

(a)

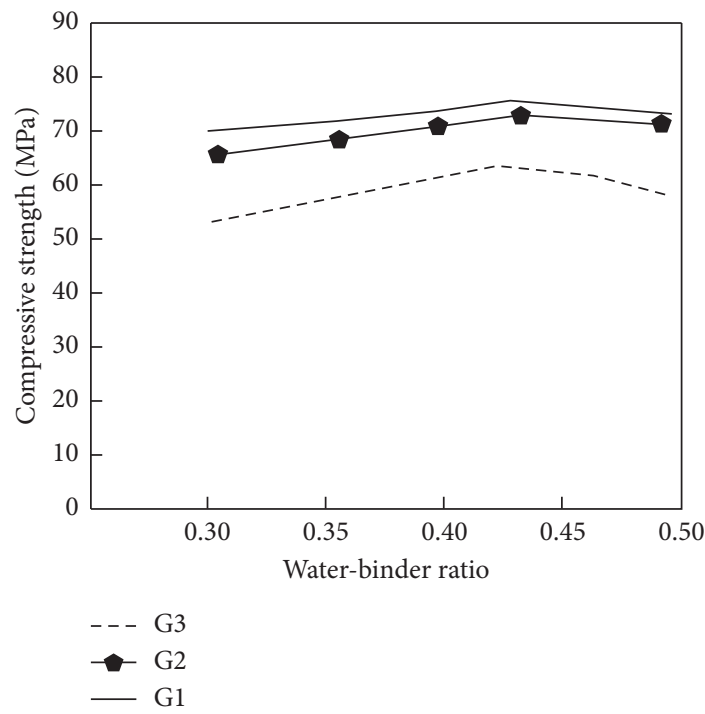

(c)

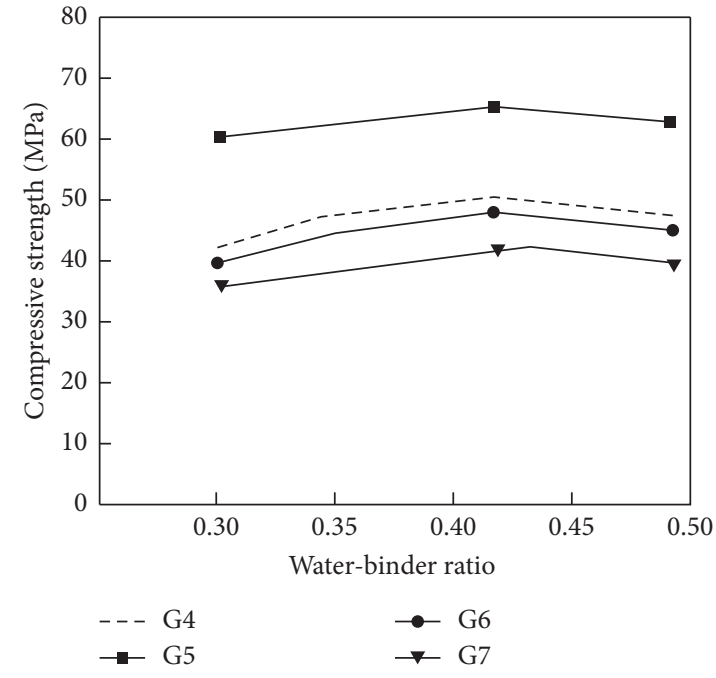

(b)

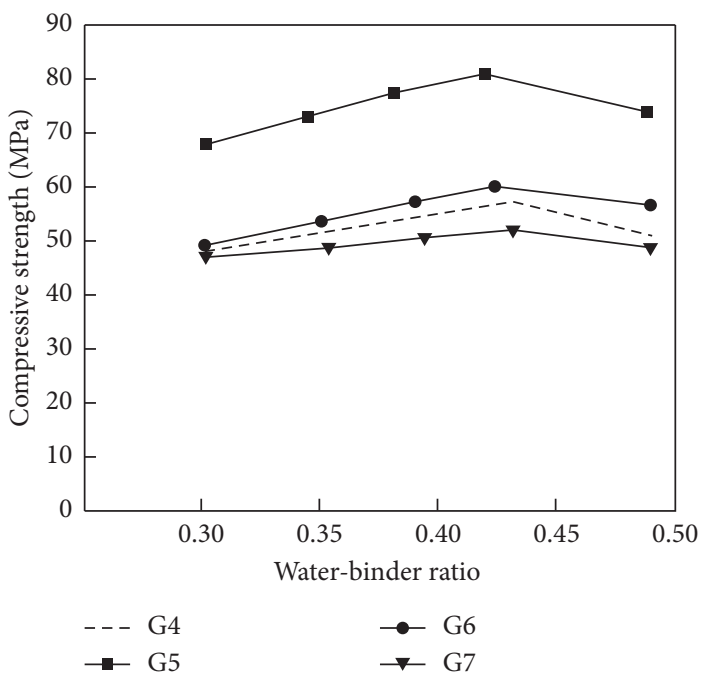

(d)

Figure 6: The variation of compressive strength of coal gangue-based polymer concrete with water-binder ratio. (a) Seven-day compressive strength (G1-G3). (b) Seven-day compressive strength (G4-G7). (c) 28-day compressive strength (G1-G3). (d) 28-day compressive strength (G4-G7).

flexural strength of coal gangue geopolymer concrete at $3 \mathrm{~d}$, $7 \mathrm{~d}$, and $28 \mathrm{~d}$ increase with the increase of water-binder ratio; when the water-binder ratio is greater than 0.43 , the compressive strength and flexural strength of coal gangue geopolymer concrete decrease with the increase of waterbinder ratio. It can be inferred that the optimum waterbinder ratio of coal gangue-based geopolymer concrete is 0.43. At the same time, it is found that the compressive strength and flexural strength of coal gangue-based geopolymer concrete with dry powder activator change with the water-binder ratio are greater than those of coal ganguebased geopolymer concrete with $\mathrm{NaOH}$ solution. Therefore, the water-binder ratio should be strictly controlled in the preparation process of dry powder activator coal ganguebased geopolymer concrete.
3.6. Effect of Sand Ratio on Compressive Strength and Flexural Strength. The changes of compressive strength and flexural strength of geopolymer concrete cured at room temperature with sand ratio are studied, as shown in Figures 8 and 9.

It can be seen from Figures 8 and 9 that no matter what activation method is adopted when the sand ratio changes from 0.25 to 0.37 , the $3 \mathrm{~d}$ and $7 \mathrm{~d}$ compressive strength and flexural strength of coal gangue geopolymer concrete increase with the increase of sand ratio when the sand ratio is greater than 0.37 , the $3 \mathrm{~d}$ and $7 \mathrm{~d}$ compressive strength and flexural strength of coal gangue geopolymer concrete decrease with the increase of sand ratio when the sand ratio changes from 0.25 to 0.40 , the $28 \mathrm{~d}$ compressive strength and flexural strength of coal gangue geopolymer concrete increase with the increase of sand ratio, when the sand ratio is greater than 0.40 , 

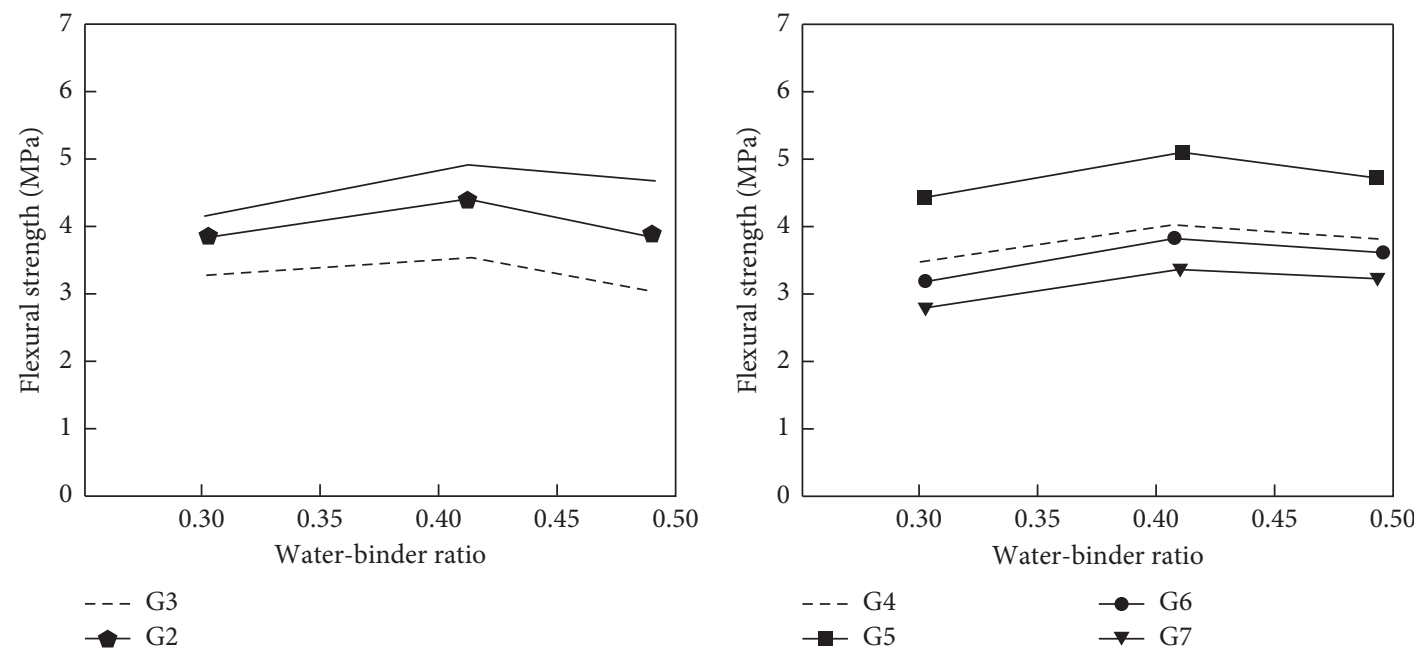

(a)

(b)
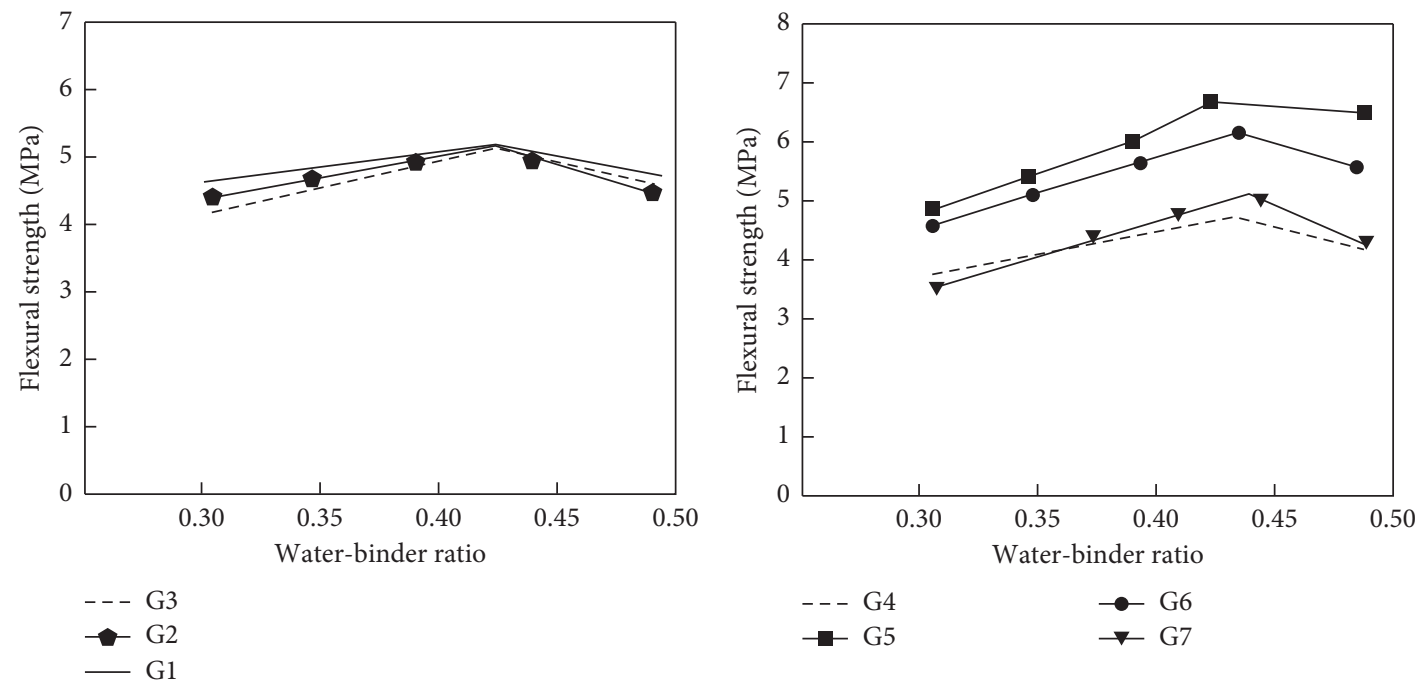

(c)

(d)

Figure 7: The variation of flexural strength of coal gangue-based polymer concrete with water-binder ratio. (a) Seven-day flexural strength (G1-G3). (b) Seven-days flexural strength (G4-G7). (c) 28-day flexural strength (G1-G3). (d) 28-day flexural strength (G4-G7).
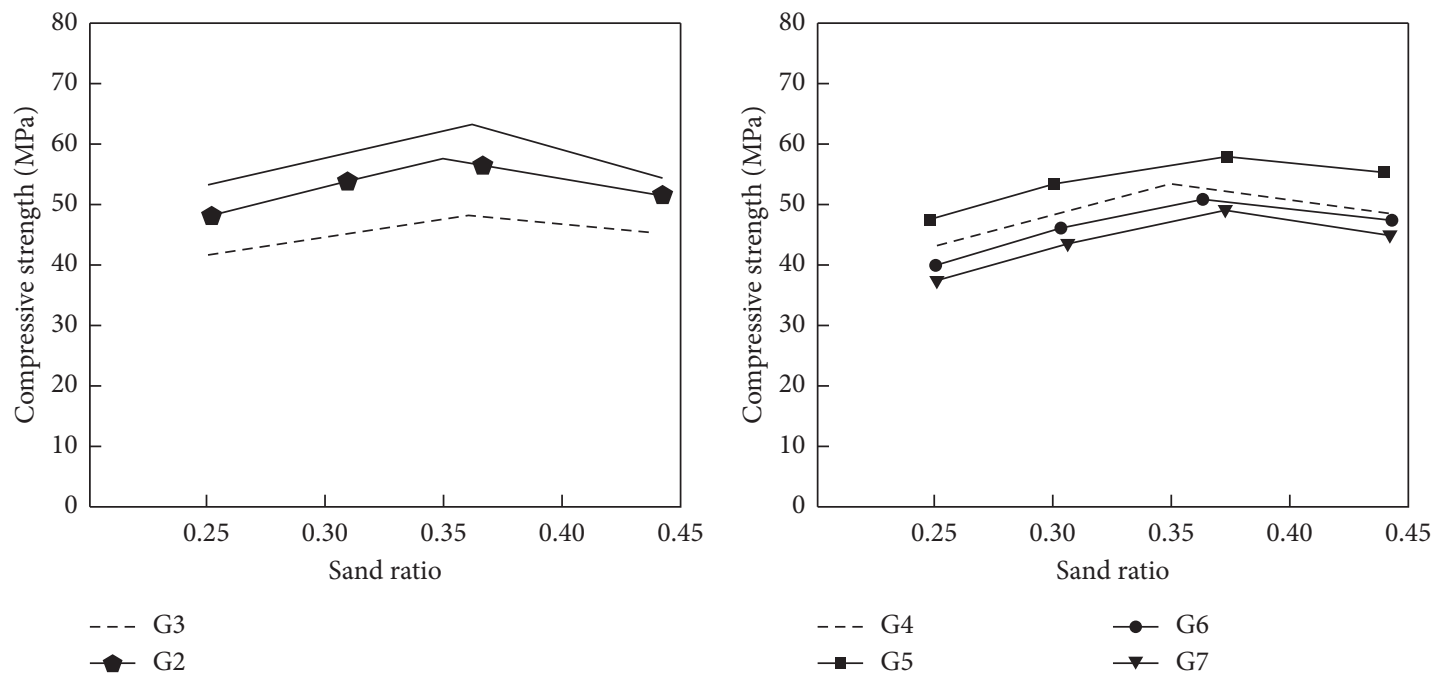

(a)

(b)

FIgURE 8: Continued. 

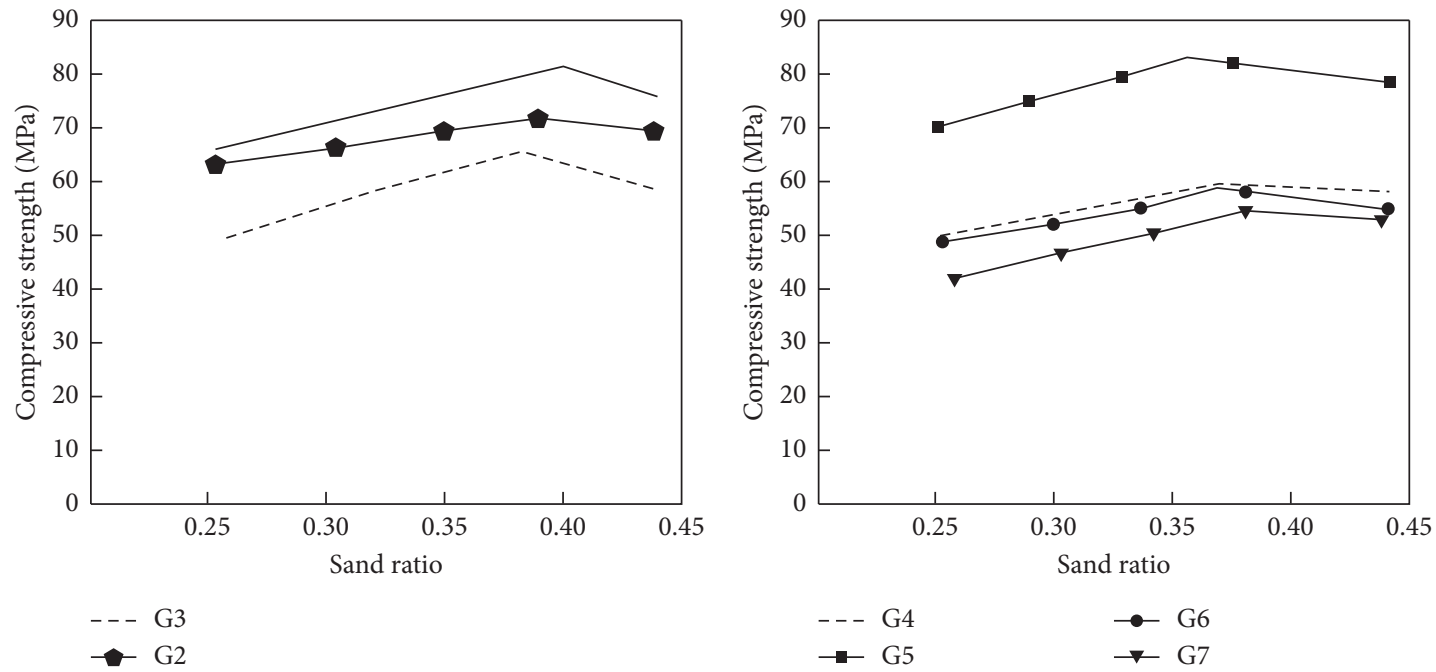

(c)

(d)

FIGURE 8: The variation of compressive strength of coal gangue-based polymer concrete with sand ratio. (a) Seven-day compressive strength (G1-G3). (b) Seven-day compressive strength (G4-G7). (c) 28-day compressive strength (G1-G3). (d) 28-day compressive strength (G4-G7).
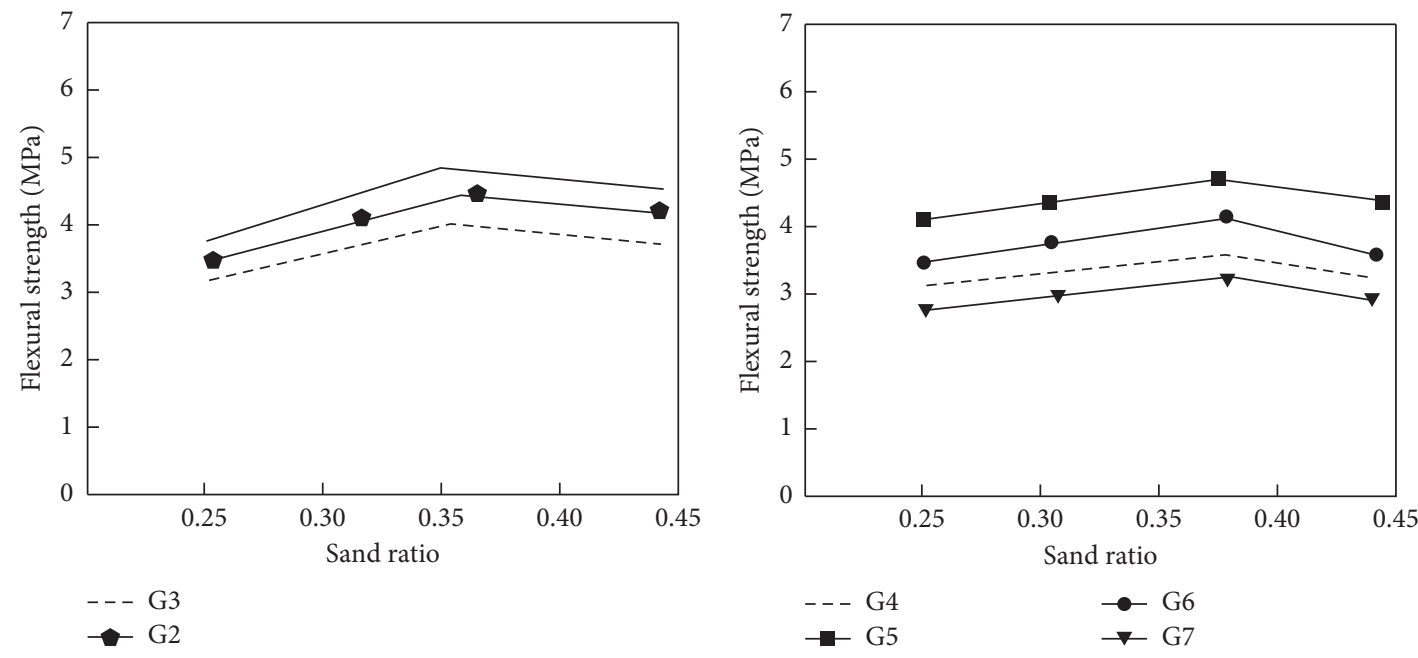

(a)

(b)

FIGURE 9: Continued. 


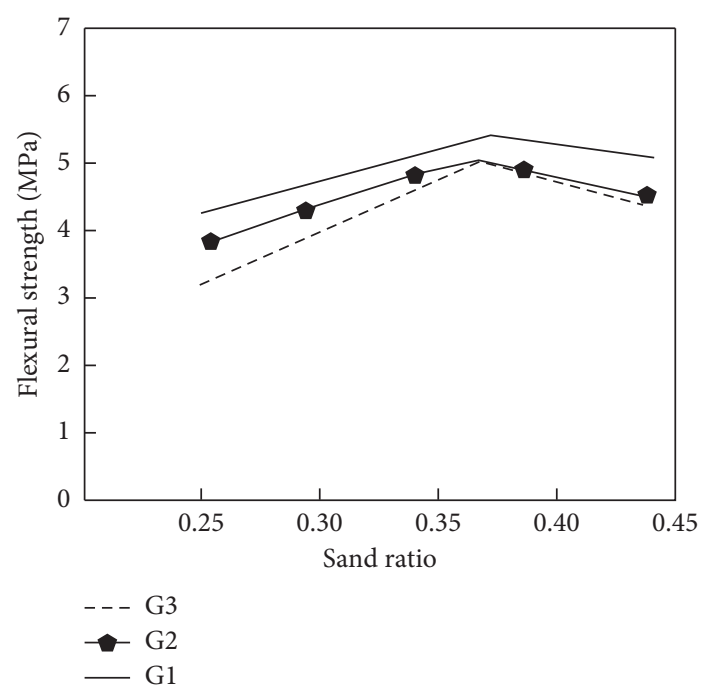

(c)

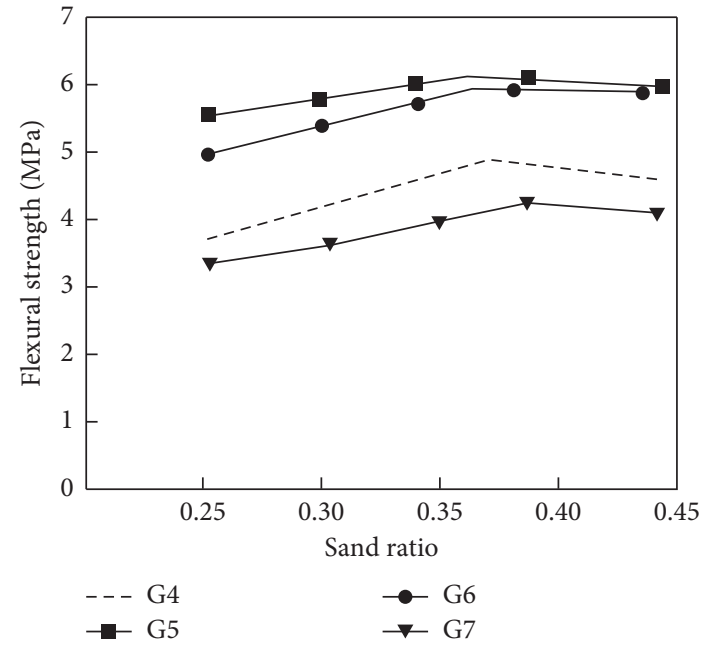

(d)

FIgURE 9: The variation of flexural strength of coal gangue-based polymer concrete with sand ratio. (a) Seven-days flexural strength (G1-G3). (b) Seven-day flexural strength (G4-G7). (c) 28-day flexural strength (G1-G3). (d) 28-day flexural strength (G4-G7).

the $28 \mathrm{~d}$ compressive strength and flexural strength of coal gangue geopolymer concrete decrease with the increase of sand ratio. It can be inferred that the optimum sand ratio of coal gangue-based geopolymer concrete is $0.37-0.40$.

\section{Conclusions}

A new type of coal gangue concrete was prepared by mixing sodium hydroxide and calcium carbonate to prepare an alkaline dry powder activator and mixing with coal gangue and fly ash as a cementitious material, and its basic mechanical properties were studied. The properties of this new type of coal concrete were compared with coal gangue activated by $\mathrm{NaOH}$ solution and ordinary concrete. The main conclusions are as follows:

(1) The compressive strength and flexural strength of coal gangue concrete activated by dry powder are higher than those of coal gangue concrete activated by $\mathrm{NaOH}$ solution. Among them, the compressive strength of coal gangue concrete with dry powder activator is $22.8 \%$ higher than that of coal gangue concrete with $\mathrm{NaOH}$ solution activator on average, and the flexural strength is $19.7 \%$ higher on average.

(2) The increase of calcium carbonate content in dry powder activator will reduce the compressive strength and flexural strength of coal gangue concrete, and too large or too small $\mathrm{NaOH}$ content in dry powder activator is not conducive to the development of coal gangue concrete strength.

(3) Whether it is activated by dry powder or $\mathrm{NaOH}$ solution, the strength of coal gangue concrete increases with the increase of curing time. However, the strength increase of coal gangue concrete with dry powder activator is greater than that of coal gangue concrete with $\mathrm{NaOH}$ solution.

(4) The optimum curing temperature of coal gangue concrete is $100^{\circ} \mathrm{C}$, the optimum water-binder ratio is 0.43 , and the optimum sand ratio range is 0.37 to 0.40 . In addition, the water-binder ratio should be strictly controlled during the preparation process of dry powder activator coal gangue concrete.

\section{Data Availability}

The data used to support the findings of this study are available from the corresponding author upon request.

\section{Conflicts of Interest}

The authors declare that they have no conflicts of interest.

\section{Acknowledgments}

This study was supported by the Open Foundation of Guangxi Key Laboratory of Embedded Technology and Intelligence, Guangxi Key Laboratory of Geomechanics and Geotechnical Engineering (GUIKENENG19-Y-21-2), Guangxi Key Laboratory of New Energy and Building Energy Saving Foundation (Gui Keneng 19-J-21-14), Joint Cultivation Program of National Natural Science Foundations of Guangxi (2019GXNSFAA245037), Guangxi Youth Innovative Talents Research Project (Guike AD19245012), and Scientific and Technology Startup Foundation of Guilin University of Technology (GUTQGJJ2019041 and GUTQDJJ2019042). 


\section{References}

[1] R. Pierrehumbert, "There is no plan B for dealing with the climate crisis," Bulletin of the Atomic Scientists, vol. 75, no. 5, pp. 1-7, 2019.

[2] T. D. Kelly and H. G. Van Oss, Historical Statistics for Mineral and Material Commodities: Cement Statistics, USGS, Reston, VA, USA, 2014.

[3] UNPD, World Population Prospects, The 2015 Revision: Key Findings and Advance Tables, United Nations, Department of Economic and Social Affairs, Population Division, New York, NY, USA, 2016.

[4] C. A. DiFrancesco, T. D. Kelly, D. I. Bleiwas, and M. D. Fenton, Historical Statistics for Mineral and Material Commodities: Iron and Steel Statistics, USGS, Reston, VA, USA, 2014.

[5] FAO, FAOSTAT, 2014, http://faostat.fao.org/site/626/ DesktopDefault.aspx?PageID=626\#ancor.

[6] S. A. Miller, A. Horvath, and P. J. M. Monteiro, "Readily implementable techniques can cut annual $\mathrm{CO}_{2}$ emissions from the production of concrete by over 20\%," Environmental Research Letters, vol. 11, Article ID 074029, 2016.

[7] Cembureau, Activity Report 2015, Cembureau, Brussels, Belgium, 2016.

[8] J. S. J. Van Deventer, J. L. Provis, P. Duxson, and D. G. Brice, "Chemical research and climate change as drivers in the commercial adoption of alkali activated materials," Waste and Biomass Valorization, vol. 1, no. 1, pp. 145-155, 2010.

[9] S. A. Miller, V. M. John, S. A. Pacca, and A. Horvath, "Carbon dioxide reduction potential in the global cement industry by 2050," Cement and Concrete Research, vol. 114, pp. 115-124, 2018.

[10] W. Prachasaree, S. Limkatanyu, P. Sukontasukkul, and P. Chindaprasirt, "Manuscript title: development of strength prediction models for fly ash based geopolymer concrete," Journal of Building Engineering, vol. 32, Article ID 101704, 2020.

[11] D. Khale and R. Chaudhary, "Mechanism of geopolymerization and factors influencing its development: a review," Journal of Materials Science, vol. 42, no. 3, pp. 729-746, 2007.

[12] M. Hussain, R. J. Varley, Y. B. Cheng, and G. P. Simon, "Investigation of thermal and fire performance of novel hybrid geopolymer composites," Journal of Materials Science, vol. 39, no. 14, pp. 4721-4726, 2004.

[13] A. C. Derrien, H. Oudadesse, J. C. Sangleboeuf, P. Briard, and A. Lucas-Girot, "Thermal behaviour of composites aluminosilicate-calcium phosphates," Journal of Thermal Analysis and Calorimetry, vol. 75, no. 3, pp. 937-946, 2004.

[14] L. Huang and L Tao, Experimental Study on Mechanical Properties of Non-spontaneous Combustion Coal Gangue Concrete, China University of Mining and Technology, Xuzhou, China, 2012.

[15] X. Querol, X. Zhuang, O. Font et al., "Influence of soil cover on reducing the environmental impact of spontaneous coal combustion in coal waste gobs: a review and new experimental data," International Journal of Coal Geology, vol. 85, no. 1, pp. 2-22, 2011.

[16] D. Zhang, F. Sun, T. Liu, and Z. Xu, "Mixture ratio design optimization of coal gangue-based geopolymer concrete based on modified gravitational search algorithm," Advances in Civil Engineering, vol. 2021, Article ID 6620853, 11 pages, 2021.
[17] A. Kusbiantoro, M. F. Nuruddin, N. Shafiq, and S. A. Qazi, "The effect of microwave incinerated rice husk ash on the compressive and bond strength of fly ash based geopolymer concrete," Construction and Building Materials, vol. 36, pp. 695-703, 2012.

[18] E. Ulhaq, S. Kunjalukkal Padmanabhan, and A. Licciulli, "Synthesis and characteristics of fly ash and bottom ash based geopolymers-a comparative study," Ceramics International, vol. 40, no. 2, pp. 2965-2971, 2014.

[19] J. Temuujin, A. Van Riessen, and K. J. D. MacKenzie, "Preparation and characterisation of fly ash based geopolymer mortars," Construction and Building Materials, vol. 24, no. 10, pp. 1906-1910, 2010.

[20] D. Hardjito, S. E. Wallah, D. M. J. Sumajouw, and B. V. Rangan, "On the development of fly ash-based geopolymer concrete," ACI Materials Journal, vol. 101, pp. 467472, 2004.

[21] A. M. Fernandez-Jiminez, A. Palomo, and C. Lopez-Hombrados, "Engineering properties of alkali-activated fly ash concrete," ACI Materials Journal, vol. 103, pp. 106-112, 2006.

[22] M. Olivia and H. Nikraz, "Properties of fly ash geopolymer concrete designed by Taguchi method," Materials \& Design, vol. 36, pp. 191-198, 2012.

[23] A. I. Laskar and R. Bhattacharjee, "Rheology of fly ash-based geopolymer concrete," ACI Materials Journal, vol. 108, pp. 536-542, 2011.

[24] F. Yawei, C. Liangcai, C. Dingguo et al., "Preparation and properties of alkali mineral powder inorganic polymer concrete," Journal of Building Materials, vol. 13, no. 4, pp. 524527,2010

[25] National Standard of the People's Republic of China, Standard for Test Methods of Mechanical Properties of Ordinary Concrete (GB/T 50081-2002), China Construction Industry Press, Beijing, China, 2003. 